Revue internationale de l'économie sociale

Recma

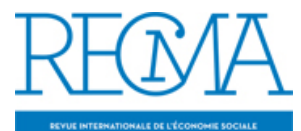

\title{
Éditions Repas : de nouvelles voies coopératives
}

\section{Jean-François Draperi}

Numéro 290, novembre 2003

URI : https://id.erudit.org/iderudit/1022166ar

DOI : https://doi.org/10.7202/1022166ar

Aller au sommaire du numéro

Éditeur(s)

Institut de l'économie sociale (IES)

ISSN

1626-1682 (imprimé)

2261-2599 (numérique)

Découvrir la revue

Citer ce compte rendu

Draperi, J.-F. (2003). Compte rendu de [Éditions Repas : de nouvelles voies coopératives]. Revue internationale de l'économie sociale, (290), 93-93.

https://doi.org/10.7202/1022166ar d'utilisation que vous pouvez consulter en ligne.

https://apropos.erudit.org/fr/usagers/politique-dutilisation/ 


\section{Editions Repas:}

\section{de nouvelles voies coopératives}

Les éditions Repas, créées à l'initiative du réseau du même nom (Réseau d'échanges de pratiques alternatives et solidaires) il y a moins de six mois, ont déjà publié trois ouvrages dans une collection intitulée "Pratiques utopiques".

Dans Moutons rebelles, Béatrice Barras retrace l'histoire trentenaire d'Ardelaine, coopérative de développement local qui, après avoir restauré le dernier moulin d'Ardèche, reconstitue la filière laine régionale, fonde un atelier de tricotage à Valence, fonde un magnifique musée dans le nord de l'Ardèche... pour n'évoquer que les activités " centrales » du collectif qui anime la Scop.

Dans une nouvelle édition enrichie de l'ouvrage sur Ambiance bois intitulée Scions... Travailler autrement? Michel Luleck montre comment ce " collectif autogéré » du plateau de Millevaches créé en 1988 a dans un premier temps questionné l'organisation de la production classique du travail avant de confronter plus fondamentalement la sphère du travail à la sphère plus large de la vie sociale, relativisant au passage la radicalité supposée des termes habituels du débat sur le temps de travail. Cette mise en question ne concerne pas que l'entreprise classique: entre autres avancées audacieuses, retenons celle qui fit passer les fondateurs d'Ambiance bois de l'idée d'une Scop à une SARL, puis d'une SARL à une Sapo, société anonyme à participation ouvrière. C'est, plus largement, la capacité permanente à questionner les normes quelles qu'elles soient qui semble spécifier la démarche collective d'Ambiance bois.

Dans La danse des ceps, Christophe Beau offre le témoignage d'une autre pratique utopique dans un secteur - l'installation en viticulture - où les normes sont prégnantes et où l'investissement est lourd. Pour dépasser les difficultés, C. Beau forme les vignes, les cultive, élève très soigneusement son vin, mais plus encore, il associe à sa démarche plusieurs dizaines de cepatou, qui sont des loueurs de vigne. L'auteur propose en effet des contrats de location de ceps de vigne en mode de consommation ou en mode de production, en quantité variable de dix-huit à quatre-vingt-dix ceps. Ces loueurs, à l'image de coopérateurs, apportent le capital en lieu et place de la banque et permettent de réduire les coûts de façon très significative... ce dont ils bénéficient, puisque chaque locataire dispose d'une livraison correspondant au niveau d'engagement.

\section{Jean-François Draperi}

\section{"Revista de estudos cooperativos "}

La Revista de estudos cooperativos, dirigée par Manuel Canaveira dos Campos, président de l'Institut Antonio-Sergio du secteur coopératif du Portugal (Inscoop), livre un numéro très intéressant ( $n^{\circ} 4$, juillet 2003), centré sur l'éducation coopérative. On relève en particulier une contribution sur le référentiel européen de l'entrepreneur social qui fonde la démarche de l'Université coopérative européenne, animé par le Groupement des collèges coopératifs (France) avec des partenaires portugais, italiens, français et belges dans le cadre d'un programme européen Leonardo. L'apport portugais est présenté par Sylvia Ferreira. La revue analyse également, sous la plume de Diva Benevides Pinho, les tendances de l'éducation coopérative au Brésil. Soulignons encore deux contributions sur la coopération vitivinicole portugaise, de Manuel Joaquim Teixeira et de Luis Manuel Fé de Pinho, le nouveau statut de société coopérative européenne par José Antonio Rodrigues et le rôle de l'OIT dans le développement coopératif par José A. V. Gomes Teixeira.

Jean-François Draperi 